\title{
青藏高原倒数第二次冰期冰 楔的发现及其意义*
}

潘保田李吉均 周尚哲

(兰州大学地理系,兰州 730000)

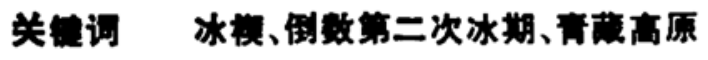

青藏高原第四纪期间受冰期气候的影响, 多年冻土下限强烈下降, 广大地区笼罩于冰缘环 境之下, 发育了大量的古冰缘遗迹. 在众多的古冰缘现象中, 冰楔假型 (Ice-wedge casts) 因其 重要的古环境重建意义而倍受注意. 70 年代末, 郭东信和张维信等根据 ${ }^{3} \mathrm{C}$ 测年资料, 指出 青藏高原存在 $23500 \pm 1200 \mathrm{a}$ B.P. 以前的末次冰期冰楔 ${ }^{[1,2)}$. 80 年代中期, 徐叔膺等在青海 共和盆地发现 ${ }^{14} \mathrm{C}$ 年代在 $17300 \pm 250$ a B.P. 左右的末次冰期砂楔和 $7750 \pm 90 \mathrm{a}$ B.P. 的全 新世小型砂楔 ${ }^{[3]}$. 近年来, 徐叔察等根据 ${ }^{14} \mathrm{C}$ 测年资料认为青海高原东 部在距 今 $33-20 \mathrm{ka}$ 和 15-10ka 发育两期末次冰期的冰楔和砂楔[4,5]. 但是, 迄今为止末见关于青藏高原有更早 时期冰椟假型发现的报道. 近两年, 我们在青藏高原东北部考察时, 发现倒数第二次冰期的冰 㮴假型, 现将初步研究成果报道于后.

\section{一、冰笑 假 型}

倒数第二次冰期的冰楔假型主要分布在青藏高原东北部的青海湖盆地东部、共和盆地东 端和南缘、兴海盆地西端、鄂拉山垭口地区及花石峡托索湖东岸等地(图 1), 海拔在 $3300 \mathrm{~m}$ 以 上.

青海湖盆地东部、共和盆地东端和南缘以及兴海盆地的冰撚假型主要发育在山麓洪积台 地的砂砾石层或基岩风化壳中; 鄂拉山垭口和花石峡地区的冰楼假型发育在冰碛物或冰水沉 积物中. 楔体内都充填细砂, 上覆棕红色古土壤和马兰黄土. 以兴海大河坝滩地区为例, 现将 发育冰样假型的地层作自下而上描述 (图 2):

(1) 砂砾石层: 青灰色, 具水平层理, 但不清晰, 含砂粘土透镜体. 砾石唐圆度较低, 次棱角或梭角状, 岩性以础岩和板岩为主, 砾径一般为 $4-5 \mathrm{~cm}$. 冰楼假型发育其内. 出露厚度最大可达 $350 \mathrm{~cm}$, 不见底.

(2) 古土壤: 棕红色, 以粘土和细砂物质为主,含小砾石, 厚度约 $20 \mathrm{~cm}$.

(3) 黄土: 灰黄色, 无层理, 以粉砂物质为主, 结构疏松, 含碳酸盐白色琣点, 厚 $80 \mathrm{~cm}$. 其中部的热释光 年代为 $30.1 \pm 2.6 \mathrm{ka}$ B.P.

(1) 古土壤: 灰黑色, 可清楚地分出两个土壤发生层. 上部㖣色较暗, 为富含有机质层; 下部颜色较浅, 含大豆的碳酸盐假菌丝体, 十分坚硬, 为碳酸盐淀积层. 中部的 “C 年代为 $4460 \pm 60 \mathrm{a}$.P. 厚 $25 \mathrm{~cm}$.

1992-01-18 收㙌，1992-02-18 收修改稿

- 国家自裙科学基金资助项目 


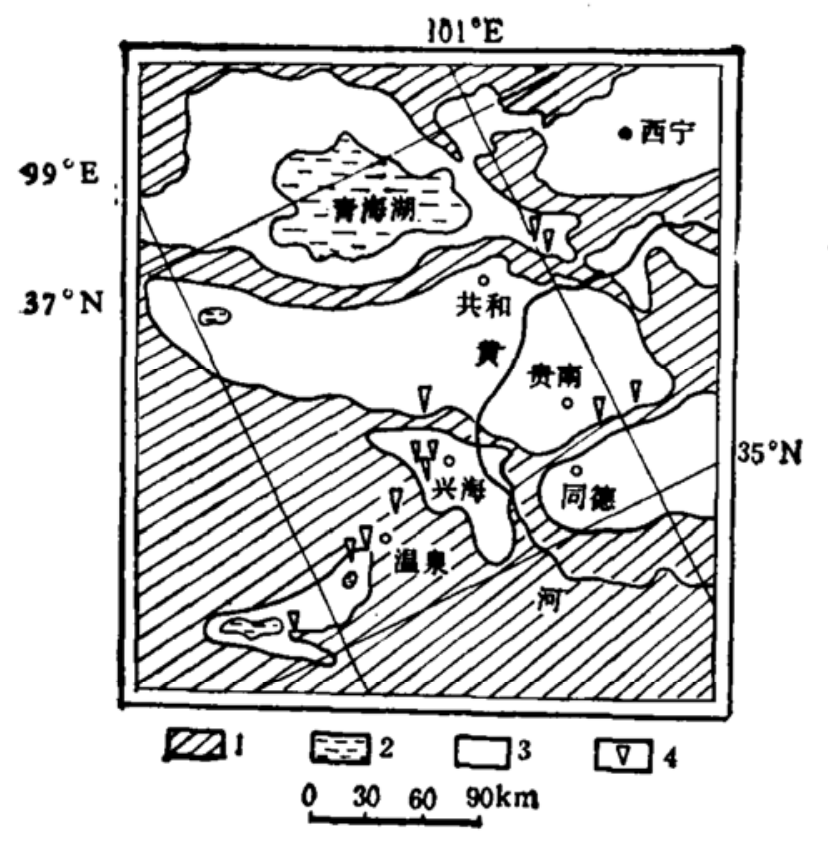

因 1 青黄高原东北部倒数第二次冰期冰楼分布图 1.基岩山地；2.胡泊；3.全地；4.冰模假形

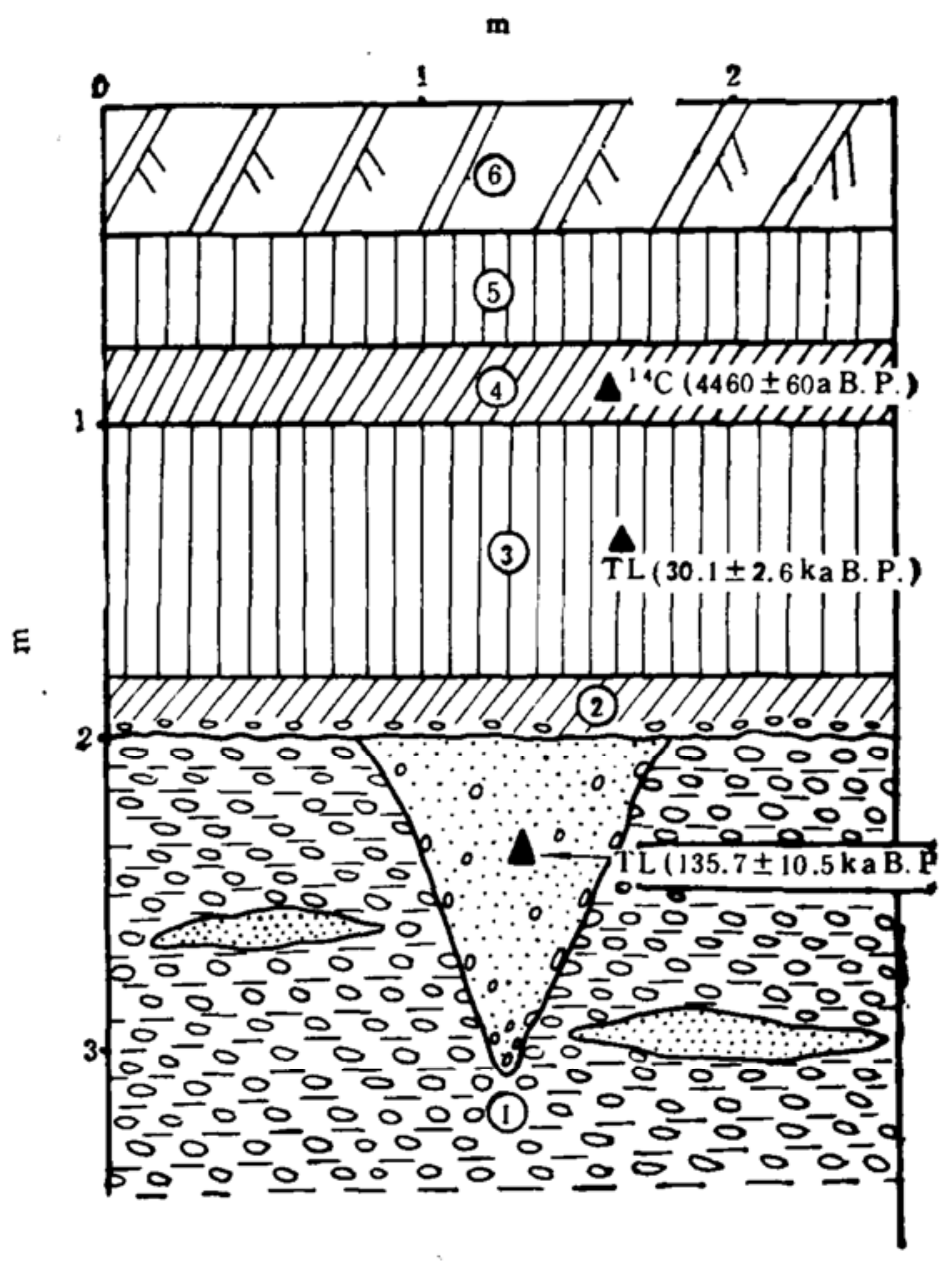

图 2 兴海大河坝滩冰椣假型剖面图

(5) 黄士: 死黄色,以粉砂为主, 无层理,结构琉松,含碳酸搵斑点. 厚 $20 \mathrm{~cm}$.

(0) 现代土埣: 黑色,含丰富的有机质. 上部为有机质层,下部为沉积层,较坚实. 厚 $45 \mathrm{~cm}$.

在兴海大河坝滩的两个路暂剖面中,共见楔体近 20 个, 楔口宽 $0.5-2 \mathrm{~m}$, 深 $0.5-2.5 \mathrm{~m}$. 形态上为窄深的尖底楔形. 楔底形态多数为单尖,少数分叉. 楔体两侧的砂砾石层强烈变形, 反映经受过强烈的挤压作用. 根据国内外的资料, 要使砾石层发生挠曲, 原生砂楔的挤压力量 难以为功. 楔内充填的灰黄色细砂在楔底和近楔壁处常有直径 $2-3 \mathrm{~cm}$ 的小砾石夹于其间, 无层理; 楼壁不平整, 且有棕红色古土壤物质贴于其上; 它们都反映楔壁在形成后, 有过滑动. 据此,我们可以推断, 细砂充填的楔体实为冰样冰融化后形成的, 楔体为冰楔假型.

根据楔内细砂的热释光年代为 $135.7 \pm 10.5 \mathrm{kaB}$. P. 下层黄土中部年代 $30.1 \pm 2.6 \mathrm{ka} \mathrm{B} . \mathrm{P}$. 和上层古土壤 ${ }^{14} \mathrm{C}$ 年代 $4460 \pm 60 \mathrm{aB} . \mathrm{P}$. 推算, 冰楔形成于 $135.7 \pm 10.5 \mathrm{kaB} . \mathrm{P}$. 以前的寒冷时 期, 即倒数第二次冰期. 其上棕红色古土壤的 $\mathrm{SiO}_{2} / \mathrm{Al}_{2} \mathrm{O}_{3}$ 为 $6.19, \mathrm{FeO}_{2} / \mathrm{Fe}_{2} \mathrm{O}_{3}$ 为 0.87 , 与著 名的临夏北塬黄土剖面中的 $S_{1}$ 相似 ${ }^{[6]}$, 看来它代表的是温暖湿润的末次间冰期;下层黄土反映 末次冰期的干冷环境; 灰黑色古土壤指示全新世高温期; 最顶部的黄土和现代土壤是高温期后 气候波动的反映.

\section{二、环境意义}

冰梗是多年冻土的标志物, 它要求十分寒冷的气候条件. 阿拉斯加现代活动冰矢分布区 


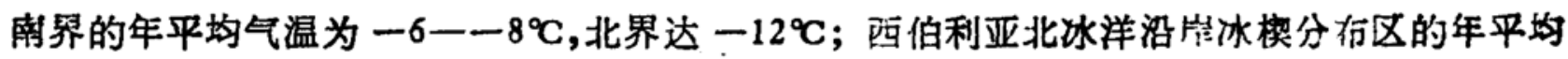
气温为 $-10^{\circ} \mathrm{C}$ 左右 $^{m}$. Rumanovskij 不仅注意到不同楔形构造形成时温度条件的差异(如形 成砂楼要平均地温至少为 $-3-5^{\circ} \mathrm{C}$, 形成永楼则为 $-5-7^{\circ} \mathrm{C}$ ); 而且还认识到不同岩性的 围岩形成冰楔地温条件的差异。通过对西伯利亚冰楔的观察，他提出生长于砂质粘性土、冲积 相细砂和砂砗石中的㶹楔要求的年平均地温上限分别为 $-2-.4^{\circ} \mathrm{C} 、-5--6^{\circ} \mathrm{C}$ 和 $-7-$ $-8^{\circ} \mathrm{C}^{[8]}$.

上述高纬冻土带冰楔杉成的温度条件对于研究本区冰楔的发育环境无疑有十分重要的参 考意义. 但是高山冻土带决不是高纬冻土带在低纬山地的简单重复. 就冰柺发育而言最关键

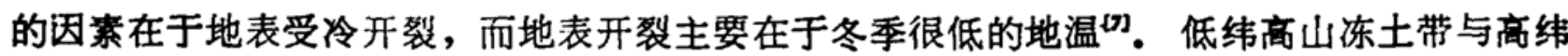
冻土带的气温条件不尽相同,冰楔发育所要求的气候条件也应有差异. 相同的年平均温度,高 纬冻土带冬季温度低,年较差大,更有利于冰楔的形成; 低纬高山冻土带冬季温度高, 年较差 小, 对地表开裂不利以. 因此若用年平均温度衡量冰楔形成温度条件的话, 低纬山地冰桠所 要求的年平均温度应低些. 现代低纬山地冰楔发育环境的特征尚未研究, 我们只好参考高纬 冻土带冰楔发育环境的研究成果。本区冰掼假型主要发育在砂砾石层和基岩风化壳中, 取 Romanovskij 提出的砂砾石层中发育冰楔需年平均地温 $-7--8^{\circ} \mathrm{C}$ 中的 $-8^{\circ} \mathrm{C}$ 作为本区倒 数第二次冰期冰楔的最高温度指标是目前最好的选择。

青海湖、共和及兴海盆地的冰楔假型是目前青藏高原东北部发现的倒数第二次冰期冰掼 的最低高度,它们应在当时冰揳分布的下限附近, 我们可以用 $-8^{\circ} \mathrm{C}$ 作为它们发育时的年平均 地温, 并据此推算烈数第二次冰期与现代的温度差 (表 1). 由表 1 看, 古今的温度差在 $12^{\circ} \mathrm{C}$

表 1 青藏高原东北部倒数第二次冰期冰榟形成时年均地温与现代差值估算

\begin{tabular}{|c|c|c|c|c|c|c|}
\hline 分布地区 & (m) & 国 岩 & $\begin{array}{c}\text { 附近气象站及 } \\
\text { 海拨高度 } \\
\text { (m) }\end{array}$ & $\begin{array}{c}\text { 年平均人温 } \\
\text { (ช) }\end{array}$ & $\begin{array}{c}\text { 年平均地温 } \\
\text { ( ' C) }\end{array}$ & 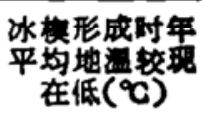 \\
\hline 等海湖东岸 & 3350 & 红层风化売 & 江西沟(3239.4) & 0.7 & 3.7 & 12 \\
\hline 共和盆地河卡 & 3300 & 砾石层 & 河卡(3245.6) & 1 & 3.8 & 12 \\
\hline 共和盆地东端 & 3300 & 砂砾石层 & 贯南(3200.6) & 2.0 & 3.1 & 13 \\
\hline 兴海大河城滩 & 3400 & 砂砾石层 & 兴海(3323.2) & 0.9 & 3.8 & 12 \\
\hline
\end{tabular}

队上. 肓藏高原晚更部泄以来的隆起量在 $1000-1500 \mathrm{~m}^{[9]}$, 东北部较小些,若按 $1000 \mathrm{~m}$ 计算。 扣除构造上升引起的温度变化, 倒数第二次冰期的温度要下降 $17^{\circ} \mathrm{C}$ 以上. 据研究, 青藏高医 东北部末次冰期的温度下降值为 6.5-9.5 ${ }^{\circ}$ 四, 看来倒数第二次冰期是远比末次冰期寒冷的一 个时期.

冰楔的形成不仅有赖于地表开裂, 而且还需有水份进入裂隙 ${ }^{[8]}$. 因此一般说来, 冰楼要形 成在冷湿环境, 至少相对湿度要大. 青藏高原东北部倒数第二次冰期出现冰楼; 而末次冰期时 则主要发育砂楔 ${ }^{(3,5)}$, 反映气候在变干。毫藏高原上倒数第二次冰期冰川规模较末次冰期大, 除倒数第二次冰期温度低外,气候较湿可能也是原因之一. 


\section{* 辛 文}

[1] 陈信, 冰川练土,1(1979),1: 51-73.

[2]张维份,兰州大学学报(自然科学版),1979,2: 113-122.

[3]徐数等, 冰川练土,6(1984),2: 15-25.

[4]保田、徐叔岛,科学通报,34(1989),7: 534-536.

[5]俆数等, 第四届全国冰川胨.土学术会议论文选集(冻土学), 科学出版社,北京, 1990,17-24。

[6] 奉吉均等,中国科学, B 辑, 1990,10: 1086-1094.

[7] Péwé, T.L., Geol. Soc. America Special Paper, 1963, 76-81.

[8]王保来等, 冰川諒土,,13(1991),1: $67 \cdots 76$.

[9] 本吉均第, 中国科学, B 辚, 1979,6: 608-616. 